\title{
A FORMAÇÃO QUE TEMOS E A QUE QUEREMOS: um olhar sobre os discursos*
}

Osvaldo Peralta Bonetti** Maria Henriqueta Luce Kruse ${ }^{\star \star \star}$

\section{Resumo}

O estudo procura aprofundar o conhecimento sobre as ações e políticas construídas para garantir a formação dos profissionais que trabalham nos serviços do Sistema Único de Saúde, considerando a relação direta e intrínseca entre a formação e a qualidade final do mesmo. Dividida em três eixos, aqui denominados de vozes, buscamos identificar, através dos discursos do controle social da área da saúde, da gestão do sistema e da formação, representada pelas escolas de enfermagem, quais são as críticas e proposições referentes ao tema da formação profissional para o SUS. O texto aborda os termos utilizados no contexto do ensino profissional, assim como a reflexão crítica sobre as novas tendências e paradigmas que estão em pauta nos debates e discussões atuais.

Descritores: educação em enfermagem; educação superior; políticas de saúde

\section{Abstract}

This research has the purpose of gaining more understanding about the actions and policies put in place in order to ensure the training of professionals that work in the services of the State Health Care System, considering the direct and intrinsic relation between the education and its final quality. Broken down into 3 perspectives, here labeled as voices, we have tried to identify, by means of the discourses on social control in the area of health, the system's administration, and education represented by the schools of nursing, what are the criticisms and propositions concerning the theme of professional training for the State Health Care System. The text deals with the terms used in the context of professional training, as well as a critical reflection about the new tendencies and paradigms that are on the agenda in current debates and discussions.

Descriptors: nursing education, state health care system, nursing, public health, health policies

Title: The education that we have and the one we want: a perspective on discourses
\end{abstract}

\section{Resumen}

El estudio busca profundizar el conocimiento sobre las acciones y políticas construidas para garantizar la formación de los profesionales que trabajan en los servicios del Sistema Único de Salud, considerando la relación directa e intrínseca entre su formación y su calidad final. Dividida en tres ejes, aquí denominados de voces, buscamos identificar, a través de los discursos del control social del área de la salud, de la gestión del sistema y de la formación, representada por las escuelas de enfermaje, cuales son las críticas $y$ proposiciones referentes al tema de la formación profesional para el SUS. El texto aborda los términos utilizados en el contexto de la enseñanza profesional, así como una reflexión crítica sobre las nuevas tendencias y paradigmas que están en pauta en los debates y discusiones actuales.

Descriptores: educación en enfermaje, sistema único de salud, enfermaje, salud pública; políticas de salud

Título: La formación que tenemos y la que queremos: una mirada sobre los discursos

\section{Introdução}

Um currículo é um recorte dos conhecimentos desejáveis para a formação e, como tal, possui uma determinada ordem. Nesta, estão em luta visões de mundo e a possibilidade de produção de representações, narrativas, significados sobre coisas e seres do mundo ${ }^{1}$. Assim, o currículo não deve prestarse apenas a formação profissional mas precisa instigar e ampliar a visão de mundo, aperfeiçoando os acadêmicos e acadêmicas em sua condição de cidadãos e cidadãs. Observamos que a formação de enfermeiras e enfermeiros no Brasil apresenta grande diversidade, principalmente se temos como foco os currículos das escolas de enfermagem. Este é um fato preocupante pois, embora não seja desejável a existência de um currículo padronizado, esta discrepância não oferece a garantia da qualidade que desejamos.

A cidadania pressupõe a ciência de deveres e direitos. No Brasil, a saúde é um direito de todos e dever do Estado, garantida no artigo n 196 da Constituição Federal de 1998 e, também, em outros artigos de leis complementares como a de n 8080 de 1990. As deliberações do Estado intervêm na lógica da formação, possibilitando a superação do modelo hegemônico político pedagógico vigente. Sendo assim, as universidades públicas, influenciadas pelo Estado, devem participar articuladamente na construção de políticas que visem a reordenação da formação dos profissionais de saúde, a fim de efetivar seu comprometimento social, afirmação que também encontra amparo na Norma Operacional Básica de Recursos Humanos (NOB - RH/SUS). Neste contexto, é necessário que se implemente um sistema público de saúde comprometido e condizente com as demandas sociais sendo, portanto, necessária a formação de profissionais capazes de atuar neste sistema.
O Sistema Único de Saúde (SUS) possui uma natureza ideológica de extrema simplicidade, embasada em princípios de igualdade e cidadania. Porém, para seu pleno funcionamento, necessita de uma complexa rede de articulações e pactuações. Um dos possíveis entraves parece ser a dificuldade dos profissionais inseridos no SUS em conduzi-lo, tanto no aspecto administrativo, quanto no assistencial. Para minimizar este problema deve haver um redirecionamento dos aparelhos formadores em saúde, no sentido do fortalecimento do SUS, ou seja, a revisão das estruturas curriculares, para que sejam enriquecidas com o debate relativo à política, legislação e trabalho no SUS, bem como, através da articulação dos aparelhos formadores com os segmentos do controle social do SUS ${ }^{(2)}$.

Vivemos hoje numa sociedade na qual o capital financeiro é quem dita as regras a serem seguidas, quais as necessidades de trabalho e sua forma de organização. Esta é a lógica de algumas instituições de ensino, cedendo principalmente às necessidades do mercado quando articulam suas diretrizes e tendências na formação. Discordamos da visão corrente de que o mercado resolverá os problemas na formação acadêmica, pois quem deve se apropriar de tal tarefa é o Estado, cumprindo com o seu papel de responsável pela estruturação, regulação, controle e ajustes na política de recursos humanos para a saúde ${ }^{(3)}$.

Este trabalho tem por objetivo analisar os discursos referentes à reforma dos currículos na área da saúde e suas implicações na formação de profissionais de enfermagem capazes de atuar no Sistema único de Saúde. Os materiais analisados são textos, documentos e artigos, aqui vistos como discursos autorizados sobre o assunto, já que partem de pesquisadores, universidades e principalmente do governo.

\footnotetext{
* Trabalho de conclusão de curso apresentado à disciplina Estágio Curricular da Escola de Enfermagem da Universidade Federal do Rio Grande do Sul (EEUFRGS). **Aluno da Graduação, $8^{\circ}$ semestre 2003. EEUFRGS. ***Enfermeira. Doutora em Educação. Professora Adjunta da EEUFRGS. E-mail do autor: kruse@uol.com.br
} 
Esses discursos mostram-se produtores de realidade em determinadas condições históricas. Partindo dessa premissa, não é o sentido per si que buscamos neles, mas sim a função que lhes é atribuída e os efeitos de verdade que produzem(4).

\section{Questões e método}

Com o objetivo de conhecer os discursos autorizados sobre a formação em enfermagem, especificamente sobre a formação para o Sistema Único de Saúde, buscou-se identificar as vozes que se cruzam e quais as temáticas recorrentes em relação ao assunto. Este trabalho tem como propósito principal fomentar discussões sobre a necessidade do reordenamento da formação de recursos humanos para o SUS. Também pretende auxiliar as representações discentes a ampliarem seus debates acerca do assunto, instigando a reflexão de acadêmicos/as acerca de sua formação, no sentido de avaliar o comprometimento social dos mesmos, possibilitando uma mudança nos seus modos de agir.

O estudo consiste em uma pesquisa bibliográfica ${ }^{(5)}$, a qual é desenvolvida através de material já elaborado, constituído principalmente de livros e artigos científicos. Nesta revisão de literatura foram utilizados textos publicados em periódicos, anais de congressos, documentos governamentais, projetos da área de educação, artigos de revistas, teses, dissertações e livros. Documentos oriundos de pesquisa on-line em sites de entidades, universidades e bases de dados como BDENF, LILACS e Medline, também foram considerados.

A análise consistiu nos seguintes passos(5): leitura exploratória; leitura seletiva; leitura analítica e, por fim, a leitura interpretativa. Posteriormente, fez-se a tomada de apontamentos, anotando as idéias principais e os dados importantes em relação aos objetivos da pesquisa, como o registro dos conteúdos das obras e comentários acerca das mesmas, com base no referencial teórico.

\section{Vozes que se cruzam}

Durante o período mais repressivo da ditadura militar, enquanto as classes populares e seus representantes eram silenciados pelo regime, desenvolveu-se um pensamento transformador na área da saúde. Desta forma, a modificação no pensamento médico-social, mesmo com as vozes silenciadas, já existia, eclodindo com a organização dos movimentos sociais. Assim o movimento sanitário encontra seu referencial nas classes trabalhadoras e populares ${ }^{(6)}$

Partindo desta referência, este trabalho é dedicado a todas as "vozes", que influenciaram ou protagonizaram estes discursos que são, por hora, utilizados neste trabalho. Elas reivindicam e lutam pela efetivação de uma saúde pública preservadora dos direitos sociais dos brasileiros.

\subsection{Vozes do Controle Social}

Iniciamos a análise pelas vozes do controle social, provenientes das Conferências Nacionais de Saúde (CNS). Estas Conferências têm sido um espaço de reflexão e proposição coletiva, na qual estão representados todos os segmentos e agentes envolvidos no processo formativo, dentre estes, os usuários do SUS, constituindo-se nos principais implicados na qualidade da política de formação de recursos humanos, já que a formação se reflete fortemente na qualidade da assistência prestada.

O tema Recursos Humanos permeia as discussões desde antes da $8^{a}$ Conferência Nacional de Saúde (CNS), realizada em 1986, na qual se efetivou a criação do SUS, cujo tema foi a "Reformulação do Sistema Nacional de Saúde". Mesmo assim, iniciamos nossa análise a partir desta Conferência pela sua significância histórica. Desde então, tem sido apontada a necessidade de readequar o processo formativo aos princípios do Movimento da Reforma Sanitária, tais como a integralidade, a universalidade, a hierarquização e a resolutividade das ações de saúde. Para tanto, é necessário integrar a formação de recursos humanos aos serviços de saúde respeitando sua regionalização e hierarquização, como também a inclusão de práticas alternativas nos currículos das escolas e a necessidade de integração entre hospitais universitários e o SUS ${ }^{(7)}$.

O Movimento da Reforma Sanitária surgiu nos anos 70 , primeiramente no meio universitário, com posterior adesão de técnicos, especialistas e pensadores. Ao longo do tempo, passou pelas experiências da medicina comunitária, pelos movimentos populares e avançou no movimento municipalista. Seu principal objetivo era se contrapor à ditadura, por entendêla incompatível com as propostas de saúde coletiva preconizadas pelo movimento. Já na década de 80 , em seus encontros, esse inconformismo era expresso na denúncia da crise do setor saúde, que se encontrava fortemente marcado pela privatização da assistência e compra de serviços, verticalização e centralização administrativa, exclusivista ou classista, pois apenas tinham acesso os trabalhadores que contribuíam com a Previdência Social. Dos seus ideais e lutas nasceu o Sistema Único de Saúde.

A $1^{\text {a }}$ Conferência Nacional de Recursos Humanos, ocorrida em 1986, foi organizada para permitir o debate do tema central: "Políticas de Recursos Humanos Rumo à Reforma Sanitária". Percebe-se que desde aquele momento a formação na área da saúde vinha sendo elaborada, inclusive com algumas críticas que se conservam até hoje, como a necessidade de uma articulação mais estreita entre as instituições que prestam serviços e aquelas que formam pessoal de saúde ${ }^{(8)}$.

Nos discursos que constam do relatório desta conferência, nota-se que os diagnósticos sobre a formação de recursos humanos apresentaram muitos avanços, porém as proposições enfatizavam a capacitação e treinamento de ingresso no Sistema através de programas de especialização e pós-graduação. Pensa-se que o Movimento da Reforma Sanitária acreditava que as mudanças no ensino superior seriam decorrentes da mudança nos modelos de atenção e no mercado de trabalho, inerentes às transformações que ocorreriam no processo de democratização da área. No entanto, existiam entraves que dificultavam as mudanças, como o grande distanciamento entre os currículos e o novo conceito de saúde que se desenhava, acrescido das características das estruturas hierárquicas das universidades que não tinham e não têm a flexibilidade necessária para facilitar estas mudanças. Assim, mesmo sinalizando a necessidade de alterações nas propostas de mudança na formação, os cursos de graduação não eram percebidos como passíveis de habilitar profissionais para atuarem no SUS. A valorização da formação para o trabalho em equipe já era bastante enfatizada.

O saber na área da saúde é, por natureza, fragmentado em vários saberes, sendo que cada profissional detém apenas a área específica de sua formação para a atenção em saúde. A divisão social do trabalho faz com que haja a repetição de tarefas em determinados níveis de complexidade, hierarquizando os profissionais. Essa divisão do conhecimento científico e a hierarquização dos profissionais refletem no resultado final do trabalho. Um dos efeitos que ela produz é a precarização do saber sobre saúde que a população detém( ${ }^{(8)}$.

Ainda na $1^{\circ}$ Conferência de Formação de Recursos Humanos encontra-se uma análise do Programa de Integração Docente-Assistencial (IDA). Este programa mobilizou as universidades na década de 80. Estas identificaram como um problema a alienação da escola em relação à realidade social da população, a divergência entre a estrutura autoritária das escolas e as propostas do SUS e a desarticulação intra e interinstitucionais na relação serviços/escolas. As propostas para superar tais entraves foram: a participação ou inclusão dos espaços de ensino-aprendizagem nas comissões 
interinstitucionais de saúde em seus diversos níveis, no controle social e na pactuação do SUS; a co-responsabilização dos serviços pela produção do ensino e da pesquisa; a inclusão dos hospitais de ensino no SUS; a democratização das estruturas de escolas e serviços e uma reforma curricular que contemplasse a inclusão de novas práticas pedagógicas. No relatório, está expressa também a necessidade de se realizar "práticas extra muros" para reforçar as ações de prevenção, tornando visível a necessidade de integração entre Hospitais de Ensino/Centros de Saúde/Distritos - Escolas.

Em 1992, em meio à conjuntura caótica por que passava o sistema público de saúde, decorrente das políticas do governo Collor, acontece a $9^{a}$ Conferência Nacional de Saúde, cujo temário foi "Municipalização é o Caminho". Nesta, foi destacada a necessidade de assegurar uma política de formação e capacitação de recursos humanos, construída de forma articulada com os órgãos formadores, considerando os quadros nosológicos e epidemiológicos de cada região. Mais enfaticamente se defendia a reformulação dos currículos das carreiras da área da saúde para que se adequassem às realidades sócio-epidemiológicas e características étnicoculturais das populações, especialmente a indígena. Paralelamente à reivindicada inserção da Universidade no SUS, assegurava-se a necessidade de mecanismos de avaliação contínua do ensino em saúde. A inclusão da fitoterapia nos currículos é destacada reforçando a necessidade de terapias alternativas ou complementares na formação, uma antiga reivindicação. Atrelada à exigência da imediata regulamentação do artigo 200, inciso III, da Constituição Federal que atribui ao SUS a tarefa de "ordenar a formação dos RH", é destacada a importância da garantia de recursos orçamentários para a educação dos profissionais de saúde, bem como a importância da criação de núcleos de desenvolvimento de trabalhadores junto à gestão de recursos humanos. Ainda sobre as políticas de recursos humanos, a 9a CNS, em 1993 e a II Conferência Nacional de Recursos Humanos, tem como tema "Os Desafios Éticos Presentes na Atualidade Histórica da Sociedade Brasileira". Nesta Conferência foi produzido um denso documento sobre o tema, que fazia um alerta detalhado e preciso sobre os riscos da falta de uma política de recursos humanos para o SUS.

"Onde dá SUS, dá certo"! Esta era a chamada da 10a $\mathrm{CNS}^{7}$. Nesta, houve deliberações quanto à formação e desenvolvimento de recursos humanos em Saúde. Houve a exigência de que o Ministério da Saúde apresentasse, após ampla discussão com as entidades representativas da área um Plano de Ordenamento da Capacitação, Formação, Educação Continuada e Reciclagem de Recursos Humanos em Saúde, para deliberação pelo Conselho Nacional de Saúde. Este plano deveria ser articulado nacionalmente, inclusive com previsão de repasses financeiros específicos para essas atividades, sendo baseado nos seguintes princípios: criação de Comissões Permanentes para integração entre os Conselhos de Saúde, os serviços de saúde e as Instituições de Ensino Fundamental e Superior, para deliberar sobre a capacitação, formação, educação continuada e reciclagem dos Recursos Humanos em Saúde, a partir da ótica do SUS; estímulo à utilização das unidades e serviços do SUS como espaço prioritário para a formação de trabalhadores em saúde (sistema de saúde-escola), com a supervisão das unidades de ensino e de serviço, garantindo um intercâmbio qualificado entre essas instituições e a formação de profissionais com perfil mais compatível com o SUS ${ }^{(9)}$.

Nesta $10^{\mathrm{a}}$ Conferência é reforçada a exigência da revisão dos currículos mínimos dos cursos de nível superior da área da saúde, com a participação dos gestores do SUS e Conselhos de Saúde, adequando-os às realidades locais e regionais, aos avanços tecnológicos, às necessidades epidemiológicas e às demandas quantitativas e qualitativas do Sistema Único de
Saúde. Também se deliberou o apoio, participação e valorização de projetos de avaliação do ensino como os da Comissão Nacional de Avaliação do Ensino Médico e da Rede Unida, por parte dos Gestores do SUS e os órgãos de fomento à pesquisa. A reivindicação da integração ensino-serviço reaparece qualificada pela inclusão da comunidade, na construção da política de recursos humanos.

Os participantes da $11^{\text {a }} \mathrm{CNS}^{(10)}$ entenderam que a formação dos trabalhadores da saúde não se orientava pelas necessidades sociais em saúde. Em seu relatório final, dentre as críticas apontadas ao processo de formação, aparece a supervalorização das tecnologias e da especialização, os quais não atendem ao perfil demandado pelo SUS, pois não garantem acesso universal, qualidade e humanização da atenção com controle social. Afirmam que há uma deficiência técnica e ética no preparo para a humanização, existindo um estímulo ao "diagnóstico armado" ou pré-estabelecido, em detrimento da avaliação clínica, dando origem a um enorme número de exames subsidiários, agravando a busca e a espera pela assistência.

Ainda no relatório da $11^{\text {a }} \mathrm{CNS}$ encontra-se referência ao distanciamento entre os organismos de gestão e de participação social das instituições que propunham as políticas educacionais (Ministério da Educação, Universidades, Sociedades de Especialista). Também é destacada a inobservância da intersetorialidade na formulação e implementação das políticas públicas que regem as reformas curriculares entre Ministério da Saúde e da Educação, principalmente em relação à implementação destas nas universidades privadas. O relatório evidencia ainda a ausência do saber acadêmico na construção e na formação dos profissionais para atuarem nos modelos de gestão do SUS, o que é refletido em ações sem planejamento e em conflitos internos nas equipes de saúde ${ }^{(10)}$.

Dentre as propostas encontramos a construção de um debate "articulado e articulador" de gestores, conselheiros, trabalhadores e formadores de $\mathrm{RH}$ para implementar a NOBRH/SUS e aperfeiçoá-la, assim como introduzir o conceito de equipe multiprofissional, segundo as necessidades sociais em saúde ${ }^{(10)}$. Nota-se também a necessidade de interdisciplinaridade no processo de trabalho das equipes de saúde e nos processos de formação, porém surgem conceitos corporativos, tais como, profissionais não-médicos. Defendese que o Ministério da Saúde efetive os protocolos de ações de saúde, o que determina a necessidade da inclusão de conhecimentos sobre estes assuntos durante a formação. Reivindica-se uma canalização de recursos financeiros para a formação dos recursos humanos para o SUS, definindo o perfil profissional apropriado a partir de necessidades concretas locais $^{(10)}$. Salienta-se, ainda, a necessidade de redirecionar o papel dos aparelhos formadores em saúde (universidades e escolas técnicas) no fortalecimento do SUS e a revisão das estruturas curriculares para que se enriqueçam pelo debate da política, legislação e trabalho no SUS ${ }^{10}$. Em relação ao papel das universidades, foi reivindicado na $11^{\text {a }}$ CNS o cumprimento da deliberação da $10^{\text {a }} \mathrm{CNS}$, exigindo a revisão imediata dos currículos mínimos dos cursos de nível superior com a participação dos gestores do SUS e Conselhos de Saúde, visando à adequação das realidades locais e regionais, aos avanços tecnológicos, às demandas quantitativas e qualitativas do SUS e a implementação das novas diretrizes curriculares para o ensino médio e superior. Isto possibilitou a formação de profissionais de saúde de acordo com as políticas propostas pelo SUS, incluindo a saúde coletiva na pauta das discussões ${ }^{7}$, o que possibilitou uma articulação entre as instituições formadoras, gestores e controle social, por meio da horizontalização e democratização da gestão das escolas, para buscar a resolução dos problemas de saúde de cada região e do país como um todo, com e para a sociedade, como ocorre, 
por exemplo, na extensão universitária( ${ }^{(7)}$.

Estabeleceu-se a ressalva de que os órgãos formadores em saúde deveriam ter seus papéis revistos para que se enriqueçam com o debate das políticas de saúde, da legislação e do trabalho no SUS. A articulação do controle social com os órgãos formadores e a realidade do SUS foi proposta mais uma vez, sendo enfatizada a importância do reordenamento dos currículos de formação na área da saúde.

Quanto à formação na área da saúde destaca-se a importância de estabelecer regras nacionais de articulação entre o MEC, as Sociedades de Especialistas e o CNS e passar ao SUS a decisão sobre especialidades a serem criadas ou extintas, bem como a regulamentação da diversificação dos papéis das profissões de saúde e das oportunidades formativas nos ambientes de trabalho da saúde ${ }^{(10)}$. Com o objetivo de orientar a formação de profissionais, a regulação e o papel das universidades, os Conselhos de Saúde e de Educação deveriam criar critérios rígidos que regulassem a criação de novas instituições formadoras, a abertura de cursos e a ampliação de vagas na área de saúde e, dentre eles, fosse considerada a necessidade social de cada região, em cumprimento à Lei $n$. $8.080 / 90$. Também foi recomendada a participação da comunidade nos Conselhos Superiores das Universidades como forma de contribuir, acompanhar e fiscalizar a formação dos profissionais de acordo com as necessidades sociais da população(10).

Paralelamente às Conferências, o Conselho Nacional de Saúde organizou oficinas e seminários descentralizados a fim de sistematizar e aprofundar as discussões acerca da política de recursos humanos. Deste trabalho resultou a elaboração dos "Princípios e Diretrizes para uma Norma Operacional Básica de Recursos Humanos para o SUS", que se constitui em um material propositivo de ações e normas estabelecedoras de um maior comprometimento dos gestores federal, estadual e municipal, estabelecendo como necessidade que o modelo de educação permanente seja baseado nas atribuições e competências dos trabalhadores do SUS e para equipes de trabalhadores, para tornar possível a implementação do SUS em novos modelos assistenciais e de gestão(10).

A $12^{a}$ CNS, cujo relatório final não foi finalizado, desenvolveu o tema "O Trabalho na Saúde", destacando que as mudanças no mundo do trabalho, ocasionadas pelo processo de globalização e pela incorporação de novas tecnologias, acarretariam no desafio de implantar uma política que reduza a precarização nas relações de trabalho no setor de saúde, possibilitando mais investimentos na capacitação e educação continuada dos profissionais e melhores resultados dessas ações, regulando a formação em todos os níveis para adequá-la às necessidades do sistema de saúde(11).

Cabe destacar que a afirmação de que há um grave descompasso entre a formação acadêmica e a realidade social do País tem sido freqüente nos relatórios das Conferências. Do mesmo modo, a reivindicação da efetivação do artigo 200 da Constituição Federal, que coloca sob responsabilidade do SUS ordenar a formação dos recursos humanos para a saúde, foi expressa em todas as Conferências. Também é oportuno esclarecer que a análise focaliza-se nos eixos referentes à formação contidos nos relatórios, porém explicita-se que estas reivindicações se deram por uma política de recursos humanos no seu sentido mais amplo, que reformasse a própria gestão dos Recursos Humanos da saúde, pois para a efetiva implementação do SUS, faz-se necessário o tratamento ordenado de sua força de trabalho ${ }^{(10)}$.

Por fim, analisando os discursos das vozes do controle social não se encontram as falas da população assistida por estes serviços. As falas relatadas são marcadas por vozes da academia ou dos serviços. Esta observação leva a questionar se estas vozes não se manifestam somente no que se refere aos recursos humanos ou se os relatórios que tanto as defendem não dão espaço para suas expressões em seus modos de ser e agir.

\subsection{Vozes da Gestão}

A legislação que rege o Sistema Educacional Brasileiro é a Lei de Diretrizes e Bases da Educação (LDB), instituída pela Lei n. 9.394, de 20 de dezembro de 1996. A LDB promove a descentralização e a autonomia das escolas e universidades, além de instituir um processo regular de avaliação do ensino. Para garantir as especificidades de cada curso na construção das Diretrizes Curriculares, são estabelecidos um conjunto de orientações, pareceres e resoluções.

Até o ano de 1999, o Conselho Nacional de Educação (CNE) estabelecia os currículos mínimos dos cursos de graduação com validade nacional, devendo as instituições observar rigorosamente suas disposições, quando da elaboração de seus currículos plenos. Esta política de formação pretendia produzir um profissional "estandardizado" (padronizado) para se adaptar ao mercado de trabalho especializado, o qual seria ditado pelas relações competitivas características do capitalismo, propondo um profissional mais adaptado às necessidades regionais, respeitando as vocações institucionais e locais ${ }^{(12)}$.

No Parecer $n^{\circ} 776 / 97$, intitulado "Orientações para as Diretrizes Curriculares dos Cursos de Graduação" (DCN) observamos a crítica ao modelo dos currículos mínimos, que, segundo este documento, caracterizam-se por uma excessiva rigidez, ferindo a liberdade concedida às Instituições de Ensino Superior pela LDB em relação à elaboração de seus currículos. Avalia, ainda, que esta uniformização trouxe um certo nivelamento entre estas instituições ou "semelhança formal" como refere, porém não garantiu a qualidade desejada, assim como as inovações e a benéfica diversificação da formação oferecidaA legislação que rege o Sistema Educacional Brasileiro é a Lei de Diretrizes e Bases da Educação (LDB), instituída pela Lei n. 9.394, de 20 de dezembro de 1996. A LDB promove a descentralização e a autonomia das escolas e universidades, além de instituir um processo regular de avaliação do ensino. Para garantir as especificidades de cada curso na construção das Diretrizes Curriculares, são estabelecidos um conjunto de orientações, pareceres e resoluções.

Até o ano de 1999, o Conselho Nacional de Educação (CNE) estabelecia os currículos mínimos dos cursos de graduação com validade nacional, devendo as instituições observar rigorosamente suas disposições, quando da elaboração de seus currículos plenos. Esta política de formação pretendia produzir um profissional "estandardizado" (padronizado) para se adaptar ao mercado de trabalho especializado, o qual seria ditado pelas relações competitivas características do capitalismo, propondo um profissional mais adaptado às necessidades regionais, respeitando as vocações institucionais e locais ${ }^{(12)}$.

No Parecer $n^{\circ} 776 / 97$, intitulado "Orientações para as Diretrizes Curriculares dos Cursos de Graduação" (DCN) observamos a crítica ao modelo dos currículos mínimos, que, segundo este documento, caracterizam-se por uma excessiva rigidez, ferindo a liberdade concedida às Instituições de Ensino Superior pela LDB em relação à elaboração de seus currículos. Avalia, ainda, que esta uniformização trouxe um certo nivelamento entre estas instituições ou "semelhança formal" como refere, porém não garantiu a qualidade desejada, assim como as inovações e a benéfica diversificação da formação oferecida $^{(13)}$. No entanto, não fica claro quais seriam estas inovações necessárias e benéficas para a formação do profissional que vai atuar no SUS. Neste parecer também é referenciada a importância de se rever a tradicional burocratização dos cursos, que assumem uma postura dicotômica em relação às atuais tendências contemporâneas que consideram a formação ao nível da graduação como uma 
etapa inicial de formação, sendo necessária uma posterior especialização, bem como à crescente heterogeneidade, tanto da formação prévia como das expectativas e dos interesses dos alunos. Este discurso não estaria se contrapondo àquelas vozes do controle social que reivindicavam uma melhor formação profissional no período de graduação? Não se estaria criando um novo espaço ou abertura para a cultura da especialização? Quais seriam estas expectativas que não são contempladas nos currículos?

Encontra-se também, no mesmo parecer, a indicação de que as novas diretrizes curriculares devem se pautar pela tendência de redução da duração dos cursos de graduação. Porém, não há explicação sobre que tendência seria esta, qual seria a sua origem? Seria proveniente da visão das políticas neoliberais, defensoras da diminuição dos papéis do Estado, na busca de menor comprometimento com o processo educativo? O parecer também aponta a necessidade da fundamentação em cada área ou campo de saber, para que o estudante se sinta incentivado a busca ativa, ou seja ao estudo independente, visando seu crescimento intelectual e profissional. Que leitura deve ser feita desta proposição? Seria uma estratégia para possibilitar a diminuição da carga horária, ou o Ministério da Educação, ao propô-la, estaria manifestando sua preocupação com a construção político emancipatória dos sujeitos?

Este parecer que orienta a construção das Diretrizes Curriculares Nacionais indica ainda que os currículos deveriam ser construídos preservando a liberdade das Instituições Superiores em estabelecer a carga horária e os conteúdos necessários para a formação profissional. A autonomia no contexto educacional que temos hoje, onde predominam entidades privadas no oferecimento dos cursos superiores, não ameaçaria alguns dos princípios centrais da formação de recursos humanos privilegiando a formação para o mercado de trabalho? No mesmo parecer, também é salientada a necessidade de aliar a teoria à pratica através de estágios, estudos e pesquisas independentes, como também, a participação na extensão universitária.

Em 2001, é publicado um novo Parecer, o de $n^{\circ}$ 583/ 2001. Neste, as proposições e observações do anterior são reafirmadas, sendo definida a duração, carga horária e tempo de integralização dos cursos, o que será objeto de um Parecer e/ou uma Resolução específica da Câmara de Educação Superior. Dentre os pontos levantados encontra-se: o perfil do formando/egresso/profissional; o projeto pedagógico, que deverá orientar o currículo para um perfil profissional desejado; competência/habilidades/atitudes; habilitações e ênfases; conteúdos curriculares; organização do curso; estágios e atividades complementares; acompanhamento e avaliação(14). Neste mesmo ano de 2001, o MEC institui as Diretrizes Curriculares Nacionais do Curso de Graduação em Enfermagem, através da Resolução CNE/CES nº 3, substituindo o conceito de "currículo mínimo" para as profissões superiores pelo conceito de "diretrizes curriculares". O documento que institui as diretrizes foi ou deveria ter sido construído em um processo colaborativo, desencadeado no ano de 1997, quando então o MEC provocou a discussão de sua construção.

Construído pelo Fórum de Pró-Reitores de Graduação (ForGrad), o qual teve importante participação no processo de construção das diretrizes, segundo o próprio MEC, o Plano Nacional de Graduação traz a referência de que as IES devem reformular suas políticas de graduação. O plano propõe que sejam superadas as práticas vigentes, derivadas da rigidez dos currículos mínimos, que se traduzem em cursos com elevadíssima carga horária, número excessivo de disciplinas encadeadas em sistema rígido de pré-requisitos. Destaca também o privilegiamento da visão corporativa das profissões, ao invés de contemplar o contexto científico-histórico das áreas de conhecimento, o atendimento às demandas existentes e a indução de novas demandas mais adequadas à sociedade(15).

A participação de nossa categoria profissional nesta construção esteve liderada pela Associação Brasileira de Enfermagem (ABEN). Para ampliar e socializar o debate acerca das DCN a enfermagem se organizou nos Seminários Nacionais de Diretrizes Curriculares (SENADEN), para coletivamente discutir os caminhos que necessitava e desejava percorrer em relação às mudanças na graduação. Embora não se encontrem críticas ao processo de construção em documentos da enfermagem, o ForGrad refere que as instituições ao construírem seus pareceres acerca das diretrizes foram pautadas pela visão ministerial, pois seguiram as determinações expressas no Edital $n^{\circ}$ 4/97 da Secretaria de Educação Superior, o qual continha um conjunto de elementos constitutivos que as diretrizes deveriam contemplar. Esta afirmativa provoca a reflexão sobre a autonomia do processo criativo da categoria de enfermagem ao discutir as novas diretrizes curriculares.

A Resolução das DCN determina as orientações que devem ser seguidas pelas instituições de ensino superior na reformulação dos seus projetos pedagógicos e conseqüentemente dos currículos dos cursos de graduação que, segundo o documento deveriam ser pautados pela ótica das competências. Currículo por competência corresponde a um conjunto de experiências de aprendizagens concretas e práticas, focadas em atividades que se realizam nos contextos ou situações reais do trabalho. Privilegia a aprendizagem em ritmo individual, gradual e o desenvolvimento da capacidade de auto-avaliação(16)

O documento instituinte das novas diretrizes curriculares para graduação em enfermagem dita o perfil esperado de enfermeiros e enfermeiras, com enfoque para a formação generalista, humanística com habilidade crítica e reflexiva, capacidade de reconhecer e intervir sobre os problemas/ situações de saúde-doença mais prevalentes no perfil epidemiológico nacional e comprometimento com a cidadania $^{(14)}$.

Para atingir este perfil são requeridos um conjunto de competências e habilidades, tais como, conhecimento técnicocientífico, agilidade na tomada de decisão, comunicação, liderança, administração e gerenciamento, como também realizar educação permanente, entre outras. O documento apresenta diretrizes que se ancoram na educação centrada na práxis, privilegiando a inserção do estudante na sua realidade concreta, o mundo do trabalho em saúde. Segundo parecer da comissão de especialistas que construíram as diretrizes, a mesma tem como concepção norteadora à visão emancipatória que forma o indivíduo para a vida, com base na educação cidadã e solidária. Neste parecer, é inserido pela primeira vez o conceito de competência como um norteador da formação. Também constam no documento os conteúdos necessários para a construção do currículo.

A flexibilização, tão utilizada no meio econômico, foi citada como tendência a ser seguida no mundo da educação e das Diretrizes Curriculares, pois o currículo baseado em competência estaria modificando a formação de enfermeiros e enfermeiras. No entanto, o distanciamento do mundo do trabalho, sem a devida adaptação às novas características estruturais, resulta na constatação de que a formação na área da saúde ainda oferta pouco prestígio à saúde coletiva na sua estrutura curricular e que a concepção hospitalocêntrica, médico-centrada e procedimento-centrada (medicalizadora) da saúde ocupa um espaço hierarquicamente superior na cultura acadêmica ou na "imagem" do trabalho em saúde (17).

A emergência dos processos de flexibilização trabalhista tem gerado fenômenos tais como ampliação do trabalho precarizado, no qual o operário multiqualificado, polivalente, deve exercer na automação, funções muito mais abstratas e intelectuais, implicando cada vez menos trabalho manual e cada 
vez mais manipulação simbólica ${ }^{(18)}$. A flexibilização no mundo do trabalho teria sido concebida em uma lógica de recomposição da hegemonia capitalista naqueles países que se encontravam em crise estrutural(18). Na educação, sua inserção nos países da América Latina estaria associada ao ajuste macroeconômico, pelo qual os mesmos se submeteram na década de 90 para superar a inflação e a estagnação econômica sofrida na década de $80^{(18)}$.

Competência é a capacidade de articular e mobilizar conhecimentos, habilidades e atitudes, colocando-os em ação para resolver problemas e enfrentar situações de imprevisibilidade, em uma dada situação concreta de trabalho em um determinado contexto cultural ${ }^{(19)}$. A competência na saúde é essencial, na medida que as necessidades em saúde são extremamente dinâmicas, social e historicamente construídas, não são estruturas fisiopatológicas ou anátomo-clínicas biologicamente determinadas e, portanto, exigem que os serviços de saúde desenvolvam dispositivos também dinâmicos e extremamente flexíveis, para escutar, retraduzir e trabalhar essas necessidades ${ }^{(20)}$.

O termo competência remete a três dimensões, sendo elas: as capacidades (recurso cognitivos), as atividades de trabalho e o contexto em que estas atividades são realizadas. Já que os métodos de avaliação da formação por competências devem ocorrer por meio de um processo gradual e articulado, mais amplo e complexo do que o diretamente observável, nenhum fazer em si, isoladamente, expressa efetivamente as competências de uma pessoa; se assim fosse, poder-se-ia pensar em formação unicamente pela perspectiva do treinamento. É imprescindível não perdermos de vista a perspectiva histórica dos processos de trabalho e de formação, pois se a formação estiver puramente voltada à esfera profissional, em detrimento de uma formação integral que abranja a dimensão de cidadania, corremos o risco de fazermos uma redução no termo competência ${ }^{(21)}$.

O reconhecimento da necessidade de mudança do currículo levou a Secretaria de Gestão do Trabalho e da Educação na Saúde a realizar o Seminário Nacional de Incentivo às Mudanças na Graduação das Carreiras da Saúde, ocorrido em maio de 2003. Neste, ficou firmada a responsabilidade do Ministério da Saúde com a formulação das políticas orientadoras da formação, cumprindo seu papel de gestor do SUS. Nas discussões são destacados alguns nós críticos ainda existentes na política de formação de recursos humanos para o SUS, como a falta de conexão ou articulação entre as políticas já existentes, as mudanças curriculares nos cursos de Medicina, Saúde da Família e a profissionalização dos trabalhadores/as de enfermagem, dentre outras, as quais continuariam sendo elaboradas e implementadas desarticuladamente, o que dificultaria a proposta de transformar a realidade. Também é discutida a preocupação com o perfil da formação profissional que estaria distante da realidade da gestão descentralizada do SUS, sendo inclusive colocada em evidência a necessária transformação do modelo tradicional de ensino nas universidades, baseado na organização disciplinar e nas especialidades, quando deveriam se contrapor ao modelo hegemônico de formação e cuidado à saúde, procurando transformar as práticas de gestão e do controle social em saúde.

A atual pedagogia da transmissão, também chamada de bancária, parte da premissa de que o conhecimento e as idéias são os pontos mais importantes da educação, logo o estudante é visto como uma página em branco. Quanto às relações estabelecidas entre os agentes envolvidos no processo educativo, sejam eles educador e educando ou professor e estudante, este ocupa um papel de agente passivo e ignorante e o professor seria aquele que detém todo o conhecimento. Como possíveis fatores que colaboram para dificultar as mudanças estão o despreparo do corpo docente, os currículos ultrapassados nos quais o ciclo básico e o ciclo clínico não se relacionam, a excessiva carga horária, a dissociação entre teoria e prática e a ênfase na assistência especializada e no uso maciço da tecnologia ${ }^{(22)}$.

Como alternativa para a estruturação pedagógica na formação, o relatório apresenta a metodologia da aprendizagem significativa. Esta requer a articulação da academia e dos órgãos de gestão na seleção dos conteúdos prioritários a serem inseridos no processo de formação do futuro trabalhador, na produção do conhecimento e desenvolvimento de competências através da aproximação dos espaços de gestão/serviços ao espaço de formação. Nesta metodologia o professor assume um novo papel, o de facilitar o processo de ensino-aprendizagem, que deve estimular o aprendiz a ter atitude ativa, crítica e reflexiva durante o processo de construção do conhecimento ${ }^{(23)}$.

No seminário acima referido, é lançada a estratégia ou política de Educação Permanente, alicerçada na necessária responsabilização dos serviços de saúde com a transformação das práticas profissionais, se configurando como espaços de construção de conhecimento comprometido com a realidade social da população usuária. A proposta de Educação Permanente estaria alicerçada na aprendizagem significativa, propondo que a capacitação dos profissionais de saúde seja enraizada na metodologia da problematização do processo e da qualidade do trabalho ofertado em cada serviço de saúde. Com isso, propõe-se transformar as práticas profissionais e a organização do trabalho, tendo como conceitos a descentralização, implantação ascendente multiprofissional e transdiciplinar, desafiando universidades e gestores a testarem sua capacidade de articulação, através da democratização de suas instituições ${ }^{(24)}$. Esta proposta pretende ser diferente da Educação Continuada que buscaria manter e estender o conhecimento profissional em qualquer área da prática médica, através da atualização de seus conhecimentos. Nela, o aprendizado é construído de maneira fragmentada, seguindo as necessidades detectadas em campos profissionais específicos, seccionados em categorias profissionais, logo distante do objeto que seria a equipe de saúde, a qual constitui a estrutura do processo de trabalho no SUS.

A Educação Continuada privilegia o ensino após a graduação, com finalidades mais restritas de atualização, aquisição de novas informações ou atividades de duração definida e através de pedagogias tradicionais ${ }^{(25)}$. Já a Educação Permanente amplia seu campo de atuação, abrangendo também a graduação e, desde então, com uma metodologia contrahegemônica, em que o educando é protagonista do processo ensino-aprendizagem, tendo como campo de estudo o próprio processo de trabalho, expressando o esforço em transformar as práticas dos serviços de saúde, revendo seus valores e conceitos. Assim, teria como eixo provocador os determinantes sociais e econômicos, inseridos nas ações pedagógicas e no espaço do trabalho.

Para garantia da integralidade nas ações de saúde e, por conseguinte do processo formativo(26), os serviços de saúde devem se adaptar a concepção da rede de cuidados, ou cadeia de cuidados progressivos ${ }^{(27)}$. Atualmente, o sistema está organizado na hierarquia de complexidade crescente (onde primeiramente se localizam as Unidades Básicas de Saúde e PSF, logo as Policlínicas e Pronto Atendimentos e por último os hospitais e centros especializados) e adotam uma postura "prescritivista" marcada pelo racionalismo funcionalista. O espaço de debate, articulação e construção destas ações ou políticas locorregionais, terá como locos os Pólos de Educação Permanente (PEP), criados pelo Ministério da Saúde através da Portaria Ministerial $n^{\circ}$ 198/2004. Segundo este documento, tais PEP seriam núcleos de articulação entre gestores municipais e estaduais do SUS, representações dos Conselhos de Saúde, instituições formadoras representadas por seus discentes e docentes, entidades das várias categorias e a 
população representada pelo controle social e movimentos sociais organizados.

Segundo a Portaria que regulamenta os Pólos de Educação Permanente, estes buscam superar os limites da formação e da prática clínica: estabelecendo vínculo, a responsabilização, a integralidade da atenção, a clínica ampliada, o conhecimento sobre a realidade, o trabalho em equipe multiprofissional e a intersetorialidade. Também se propõe a alterar a atual estrutura da verticalidade única e hierarquizada na construção das políticas de $\mathrm{RH}$, no momento em que coloca como princípio construtivo e deliberativo a gestão colegiada nestes Pólos, afirmando que tais agentes detêm os conhecimentos necessários para a construção das políticas, em conformidade com a realidade local da saúde. Esta estratégia vem ao encontro do que dita a Norma Operacional Básica de Recursos Humanos para o SUS, no sentido de que as políticas de formação de $\mathrm{RH}$ devem ser construídas respeitando o perfil epidemiológico e demográfico de cada região do país, revelando que o princípio da regionalização do SUS seria a forma organizacional que melhor garantiria a universalização do direito à saúde. Assim, as políticas deveriam estar sendo construídas o mais próximo possível das populações usuárias, para que tenham melhor capacidade de resposta às demandas da população.

\subsection{Vozes da Formação}

A primeira Escola de Enfermagem surgiu em 1923, na cidade do Rio de Janeiro, época em que o país enfrentava um forte processo de urbanização em suas capitais. Esta situação forçou o governo a construir uma política sanitária centralizada para controlar as doenças endêmicas que se alastravam pelos centros urbanos. Devido às concepções de saúde e educação existentes na época, o ensino em enfermagem já nasce desvirtuado de sua finalidade, pois a formação trazia uma forte valorização do ensino prático, porém este se dava fundamentalmente atrelado aos hospitais.

A criação das primeiras escolas foi apoiada pela Fundação Rockfeler, a qual tinha como uma de suas atividades primeiras a construção de hospitais. Isto influenciou fortemente a construção de políticas públicas, pois a Fundação detinha um alto poder político e econômico neste período ${ }^{(28)}$. Assim, o ensino de enfermagem foi centralizado na realização de práticas em serviços majoritariamente hospitalares, tornando-se então, um serviço coadjuvante da prática médica hospitalar ${ }^{(28)}$. Em 1949 ocorre a primeira mudança nos currículos de enfermagem, sendo estabelecido um prazo de sete anos para extinguir-se o ingresso nos cursos de enfermagem de estudantes cuja escolaridade fosse apenas o curso ginasial. Somente em 1961, as Escolas começam a exigir que os candidatos tivessem o curso secundário completo, correspondente ao nível médio de hoje ${ }^{(29)}$.

O currículo vigente desde 1972 não era capaz de dar as respostas necessárias às necessidades de formação da enfermeira, havendo então uma grande mobilização da categoria para construir um currículo mínimo. Em 1994 entrou em vigor um novo Currículo Mínimo Nacional, cuja elaboração foi fortemente influenciada pelas discussões ocorridas na ABEN. Porém, as divergências que este currículo buscou superar não foram resolvidas, tais como fragmentação do eixo formador, mantendo os ciclos básico e profissional, o ensino centrado no modelo médico, a dicotomia teórico-prática, a desarticulação entre conteúdos e disciplinas, e a adoção de práticas pedagógicas tradicionais ${ }^{(30)}$. Assim, concluiu-se que não estava sendo atingindo o objetivo de formar uma enfermeira critica, reflexiva, competente e transformadora da realidade ${ }^{(30)}$. Para que nosso leitor possa se situar, destacamos que neste período foi instituído o Sistema Único de Saúde, alterando assim, o modelo de atenção e gestão do setor saúde.

As DCN para os cursos de enfermagem foram construídas em um processo coletivo, através de muitos debates descentralizados, onde a categoria de enfermagem teria participado ativamente ${ }^{(31)}$. A enfermagem vem discutindo qual o profissional mais adequado para a tender as demandas sociais desde a década de 80, acompanhando a redefinição dos papéis dos profissionais de saúde que se deu com a Reforma Sanitária ${ }^{(34)}$. Encontra-se hoje em um cenário político e de saúde favorável às mudanças em todos os níveis de formação profissional, sendo que a implementação das diretrizes curriculares como estratégia para estas mudanças vêm ao encontro das necessidades de saúde da população e ao fortalecimento do SUS $^{(34)}$.

A adesão dos docentes a um novo referencial teórico é importante para a efetiva apropriação do que está sendo implementado. Observam que os discursos na área educacional provocam "modismos e encantamentos" pois muitas vezes o novo, em se tratando de proposta educativa, se configura, entre os professores, como alternativa mágica, podendo ser incorporado sem reflexão, à linguagem dos educadores gerando uma certa banalização de conceitos como o da prática reflexiva. Entre as novas "seduções" temos a pedagogia das competências, e expressões como "aprender a aprender" usadas indistintamente, como um jargão que, por si só, trariam qualidade ao processo educativo. Observa-se que caberia a educadores e educadoras reconhecer a realidade social não para elaborar uma crítica a esta realidade e, conseqüentemente, construir uma educação comprometida com as lutas por uma transformação social, mas sim, apenas para conhecer quais competências a realidade social estaria exigindo dos indivíduos ${ }^{(35)}$.

Aponta-se que as DCN propõem-se a desenvolver uma flexibilidade buscando romper com o modelo arcaico e rígido de ensino, instituindo o Projeto Pedagógico como base de gestão acadêmico-administrativa de cada curso e fornecendo os elementos das bases filosóficas, conceituais, políticas e metodológicas que definem as competências e habilidades essenciais à formação dos profissionais de saúde( ${ }^{(36)}$. Porém, esta flexibilização expressa no mercado de trabalho, produziu a realidade que temos hoje na formação, onde o desafio seria romper, tanto no nível superior como no nível técnico, com a tradição tecnicista do ensino, em virtude do próprio modelo de atenção à saúde existente no Brasil, marcado historicamente, por um certo pragmatismo e pela ênfase no aspecto curativo de atendimento $^{(37)}$.

Dentre as mudanças que as DCN trouxeram encontramos a do paradigma profissional, pois esta indica que o enfermeiro deverá ter uma formação generalista. E o que vem a ser com formação generalista? Este termo comporta múltiplas definições $^{(38)}$, o que por si só já determina uma indefinição sobre o tipo de profissional que se deseja formar. Podemos questionar se essa expressão anuncia alguma contrariedade entre conhecimento geral e especializado? O egresso deste currículo teria de ser capacitado para atuar em todos os cenários de prática? Seu objetivo seria o de enfatizar a importância da formação ir além dos aspectos técnicos, do saber fazer, atingindo outras competências?

Outro aspecto presente nos discursos é a questão da integralidade na formação. Integrar as práticas e saberes exige a articulação entre as várias disciplinas que compõem o novo currículo para formação do/da profissional de saúde, e entre serviços e instituições formadoras como também trabalhar a saúde como qualidade de vida por meio de práticas intersetoriais ${ }^{(39)}$. Desta forma, é inviável um/uma profissional ter a integralidade como valor para o exercício de sua função se essa não tiver sido ensinada durante todo o seu processo de formação ${ }^{(39)}$. Durante a formação é necessário não só abordar questões relativas à doença, envolvendo a biologia humana, o estilo de vida e a organização do sistema de atenção à saúde, mas também uma agenda de formação que inclua princípios éticos e políticos da Reforma Sanitária, privilegiando modos de 
fazer saúde que levem em conta a integralidade, a intersetorialidade e o trabalho em equipe ${ }^{(39)}$.

Em 2001, foi criado o Programa de Sustentabilidade para Implantação das Diretrizes Curriculares de Enfermagem, tendo como propósito potencializar o movimento de transformação buscado pelas Escolas/Cursos de Enfermagem. Foi desenvolvido pela Associação Brasileira de Enfermagem (ABEN), através de sua Diretoria de Educação e pelo Ministério da Saúde, em parceria com as Instituições de Ensino Superior organizadas nos Fóruns de Escolas, uma organizaçõa da ABEn que está sendo fomentada em cada Estado. Sua estratégia é articular e apoiar Faculdades/Escolas e Cursos de Enfermagem na implementação das $\mathrm{DCN}$, propondo a realização de seminários e oficinas, em cada estado e em eventos nacionais, em busca da sensibilização e mobilização para a mudança, tendo como referencial as diretrizes curriculares nacionais.

Também entendemos que é necessário apontar que, dentre as possíveis dificuldades na implementação de um currículo capaz de atender às reivindicações da sociedade brasileira, a formação do professor é uma das maiores, pois não é fácil para um professor cuja formação nunca passou por um currículo "fundamentado no humanismo", cumprir esta missão, pois a graduação historicamente tem privilegiado o tecnicismo e trazemos em nossa bagagem, obviamente, a sua influência ${ }^{(40)}$.

\section{Conflitos e convergências}

Neste momento, faz-se necessária uma reflexão sobre os conflitos e as convergências suscitadas pelos discursos que estas vozes do controle social, da gestão e da formação produzem. Esta reflexão possibilita construir um outro discurso, tão frágil ou onipotente quanto os que foram analisados, não possuindo a intenção de ser uma verdade única ${ }^{(4)}$.

Ao Analisar as vozes do Controle Social, observamos que um discurso interfere sobre o outro, estabelecendo o que se conhece por subordinação( ${ }^{(4)}$. Sendo assim, estes discursos, por mais que tenham sido construídos num espaço representativo, muitas vezes de conflitos ideológicos e divergência de opiniões, são reflexos de um contexto histórico, ou seja, são fortemente influenciados por tendências, são construídos em contextos onde as questões políticas, econômicas e do trabalho exercem grande papel em sua constituição. Logo, estas vozes são carregadas de múltiplas visões de mundo(4).

Ao descrever as vozes autorizadas a falar sobre a formação de RH para a saúde, observamos que a afirmação de que há um grave descompasso entre a formação acadêmica e a realidade social do país tem sido freqüente nos relatórios das Conferências. Percebe-se que as vozes do controle social e da gestão, pelo vocabulário que utilizam, trazem um enfoque bastante tendencioso à medicina, porém são direcionadas a toda à área da saúde. É preciso refletir, em que medida, afirmações como a de que os $\mathrm{RH}$ atuais apresentam um déficit técnico e ético no seu preparo para a humanização, encontram reflexo na formação de enfermeiras e enfermeiros. Acredita-se que, para iniciar esta análise, é fundamental problematizar a questão da desigualdade entre os currículos das escolas, privilegiando a dicotomia existente entre o campo profissional e a formação protagonizada pelos cursos.

O campo profissional se encontra em constante mutação devido às conquistas e avanços que ocorrem diariamente na organização do trabalho em saúde, e a escola nem sempre consegue acompanhá-los, por ter uma natureza intrinsecamente conservadora. A preservação desta dicotomia é defendida por quem argumenta que a escola tem o papel de legar a cultura para as novas gerações. O fato de aprender está inevitavelmente voltado para o passado e o papel do educador supõe um imenso respeito pelo passado, esta é uma atitude conservadora sem a qual a educação é total e simplesmente impossível(38).

Observa-se uma crítica à maneira desarticulada com que Ministério da Saúde e da Educação vem trabalhando na discussão da política de recursos humanos, indicando que projetos importantes estão sendo implementados sem a devida articulação e debate entre estes agentes, influenciando apenas determinada área, o que comprometeria o impacto ou transformação desejada por tais políticas. Assim, acredita-se que tais reflexões sobre o passado próximo devem estar sempre presentes nesta nova conjuntura de mudanças.

Encontra-se nos discursos da gestão a crítica ao distanciamento da formação dos espaços da gestão descentralizada do SUS. Entendemos que devemos apoiar esta descentralização da gestão fomentando a participação popular neste processo. Esta descentralização quando ditada pelo modelo das competências profissionais, busca também a precarização das relações e vínculos de trabalho. Logo, precisamos refletir sobre quais intenções e gestos nosso Estado está manifestando neste processo de mudança, quais cuidados tem tomado para não reduzir esta proposta a um simples "tira e põe" disciplinas nos currículos dos cursos. Se tivermos o ímpeto de nos constituirmos como profissionais cidadãos, comprometidos em colaborar com o resgate da cidadania dos usuários, cremos que nossa estratégia está na socialização do saber, a fim de que os usuários adquiram autonomia em seu processo de cuidado, o que viria ao encontro das vozes expressas nesta pesquisa. É possível pensar que deste respeito ou comprometimento ético provenha o reconhecimento social que tanto desejamos.

Ainda na perspectiva da gestão consideramos importante destacar que a enfermagem, dentre os cursos da saúde, é a que mais trabalha com temas como planejamento, liderança, coordenação de equipes e de serviços. Este preparo é explicitado no campo profissional quando percebemos um grande número de enfermeiros/as ocupando cargos de chefia de equipes, gerindo sistemas em secretarias de saúde. Porém devemos nos interrogar: em que medida esta atuação tem garantido a qualidade dos serviços prestados? Quais modelos de gestão estamos desenvolvendo em nosso trabalho? Deveríamos ainda, avaliar qual a influência da visão hospitalocêntrica e do modelo neoliberal nesse processo e se os conhecimentos ensinados nos cursos de graduação evoluíram suficientemente para acompanhar às novas demandas administrativas do sistema. Será que esta formação administrativa, não está muito empresarial, distante dos conceitos de saúde defendidos atualmente? Será que a qualidade da assistência, que é direito do cidadão, tem se pautado pela excelência? Quais as vivências proporcionadas aos acadêmicos de enfermagem nos processos de gestão do SUS? Como proporcioná-las em um campo marcado por um corporativismo hegemônico?

Durante a análise dos discursos percebe-se que cada qual tinha suas peculiaridades. Naqueles provenientes do controle social, assim como nos da gestão, encontra-se um tom provocativo, por vezes agressivo, no primeiro, isto se explica pelo caráter reivindicatório, já no segundo, talvez por ter uma tradição de ser o implementador das regras que, nesta lógica, os tornaria responsáveis por manter a ordem social.

Já nos discursos da formação esta característica não é tão marcante, talvez por serem os próprios autores os responsáveis pela ação prescrita nos discursos. Porém estes também trazem suas dicotomias. Mostram-se defensores da participação coletiva na construção deste processo formativo almejado, porém reafirmam que os discursos têm características ambivalentes $^{(4)}$, no momento em que, não citam a necessidade da participação popular em seus processos de mudança. Seria esta mais uma das características conservadoras apontadas pelas vozes da gestão e do controle social?

Apesar de buscar uma posição problematizadora, consideramos que sempre apresentamos alguma tendência, pois ao descrever estruturas somos contagiados pelos discursos 
dominantes ${ }^{(4)}$. No entanto, reconhece-se que o discurso é poroso à práxis e a práxis é modificada pelo discurso ${ }^{(4)}$. Assim, faz-se esta reflexão como um movimento político para que ela possa produzir novas subjetividades e novos domínios de saber.

\section{Referências}

1. Costa MV. Currículo e Política Cultural. In: Costa MV. O currículo nos limiares do contemporâneo. Rio de Janeiro: DP\&A:1998.p.37-68.

2. Ministério da Saúde (BR). Conselho Nacional de Saúde. Princípios e Diretrizes para a NOB/RH - SUS. Brasília (DF);2000.159p.

3. Santos Neto PM. Recursos Humanos em Saúde no Brasil: a necessidade do planejamento. In:.Espaço para a Saúde [online]. Disponível em: <http//www.ccs.br/espaçoparasaude/v2n1/ RHSBNP.htm>. Acessado em: 12 mar 2004.

4. Foucault M. A ordem do discurso.São Paulo:Loyola;1999.

5. Gil AC. Métodos e Técnicas de Pesquisa Social. São Paulo:Atlas;1999.

6. Escorel S. Reviravolta da Saúde: origem e articulação do movimento sanitário. Rio de Janeiro: Editora Fiocruz;1998.

7. Ministério da Saúde (BR). Relatório da $10^{a}$ Conferência Nacional de Saúde: onde dá SUS, dá certo! Brasília (DF); 1996.

8. Ministério da Saúde (BR). Relatório da $8^{a}$ Conferência Nacional de Saúde: Reformulação do Sistema Nacional de Saúde. Brasília (DF);1986.

9. Armani TB, Ceccim RB, Rocha CF. O Que Dizem a Legislação e o Controle Social em Saúde Sobre a Formação de Recursos Humanos e o Papel dos Gestores Públicos no Brasil. Porto Alegre (RS): Escola de Saúde Pública;2002.

10. Ministério da Saúde (BR). Relatório da $11^{\text {a }}$ Conferência Nacional de Saúde: efetivando o SUS: acesso, qualidade e humanização na atenção à saúde, com controle social. Brasília (DF); 2000.

11. Noronha AB. Compreendendo o Temário da Conferência. Revista RADIS - Comunicação em Saúde, Rio de Janeiro 2003;12:10-1.

12. Pierantoni $C R$, Machado $M H$. Profissões de Saúde: a formação em questão. In: ॥a Conferência Nacional de Recursos Humanos: textos apresentados. Brasília(DF):MS;1993.

13. Ministério da Educação (BR). Conselho Nacional de Educação / Câmara de Educação Superior. Parecer n. 776/1997 - Orientação para as Diretrizes Curriculares. Brasília (DF): MEC:1997.

14. Ministério da Educação (BR). Conselho Nacional de Educação. Câmara de Educação Superior. Resolução CNE/CES n. 3, de 7 de novembro de 2001: diretrizes curriculares nacionais para o curso de graduação em enfermagem. Brasília (DF): MEC;2001.

15. FORGRAD. Fórum de Pró - Reitores de Graduação das Universidades Brasileiras. Disponível em:< www.prograd.ufu.br/forgrad2004/ index.html> Acessado em: 16 maio 2004.

16. Ramos M. A Pedagogia das Competências: autonomia ou adaptação? São Paulo:Cortez;2001.

17. Ceccim RB, Bilibio LFS. Observações da Educação dos Profissionais da Saúde: evidências à articulação entre gestores, formadores e estudantes. In: Ministério da Saúde (BR).Observatório de Recursos Humanos em Saúde no Brasil: estudos e análises. Rio de Janeiro:Fiocruz;2002.

18. Deluiz N. O Modelo das Competências Profissionais no Mundo do Trabalho e na Educação: implicações para o currículo. Disponível em: <http://cefetrn.br/documento/modelo_das_competências_ profissionais.

19. Deluiz N. Qualificação, Competências e Certificação: visão do mundo do trabalho. Revista Formação, Brasília (DF) 2001;1(2):5-16.

20. Cecílio LCO. Modelos Tecnoassistenciais em Saúde: da pirâmide ao circulo, uma possibilidade a ser explicada. Cadernos de saúde Pública, Rio de Janeiro 1997;13(3):469-78.

21. Machado K. Graduação: é preciso mudar - transformações dependem de políticas de educação e de saúde. Revista RADIS, Rio de Janeiro 2002;5: 9-11.

22. Ministério da Saúde (BR) Secretaria de Gestão do Trabalho e da Educação na Saúde. Departamento de Gestão da Educação na
Saúde. Seminário sobre: Incentivos às Mudanças na Graduação das Carreiras da Saúde: caminhos para a mudança da formação e desenvolvimento dos profissionais de saúde: diretrizes para a ação política para assegurar Educação Permanente no SUS. Brasília (DF); 2003. [17p.] Disponível em:< (www.opas.org.br/rh/admin/ documentos/segetes1.pdf>. Acesso em: 2 jul 2004.

23. Pereira IMTB. Recursos Humanos e Educação: uma parceria indispensável: gestão de serviços de saúde Descentralização/ Municipalização do SUS. São Paulo:Editora da Universidade de São Paulo;2001.

24. Ministério da Saúde (BR). O CNS e a construção do SUS: referenciais estratégicos para melhora do modelo de atenção à saúde. Brasília (DF):2003.

25. Ferla AA, Fagundes SMS. Tempo de Inovações: descentralização da gestão da saúde no Rio Grande do Sul: implementando a legislação para garantir saúde de verdade e com qualidade para todos os gaúchos. In:Ferla AA, Geyer LMC, Breunig M, organizadores. A Experiência da Gestão na Saúde do Rio Grande do Sul. Da Casa Editora:Porto Alegre;2002..37-53.

26. Motta JIJ. Educação permanente em saúde: da política do consenso à construção do dissenso [dissertação de Mestrado]. Rio de Janeiro: Universidade Federal do Rio de Janeiro; 1998. Disponível em: < www.ccs.ufpb.br/nesc/Tese-;inacio.pdf>. Acessado em: 7 de mai. de 2004.

27. Buss P, Motta JIJ, NunesTCM. Novos Desafios Educacionais Para a Formulação de Recursos Humanos em Saúde. 2001. Disponível em:< http://saude.gov.br.html> Acessado em: 14 maio 2004.

28. Ceccim RB, Feuerwerker LCM. O Quadrilátero da Formação para a área da saúde: ensino, gestão, atenção e controle social. Physis: Revista de Saúde Coletiva, Rio de Janeiro 2004;14(1):41-65.

29. Cecílio LCO. Modelos Tecnoassistenciais em Saúde: da pirâmide ao circulo, uma possibilidade a ser explicada. Cadernos de Saúde Pública, Rio de Janeiro 1997;13(3):469-78.

30. Kruse MHL. Os Poderes dos Corpos Frios: das coisas que ensinam às enfermeiras [tese de doutorado em Educação]. Porto Alegre: Faculdade de Educação, Universidade Federal do Rio Grande do Sul;2003.157f.

31.Germano RM. O Ensino de Enfermagem em Tempos de Mudança. Revista Brasileira de Enfermagem, Brasília (DF) 2003 jul/ago; 56(4):336-81.

32. Faustino RLH, Moraes MJB, Oliveira MAC, Egry EY. Caminhos da Formação de Enfermagem: continuidade ou ruptura. Revista Brasileira de Enfermagem, Brasília (DF) 2003 jul/ago;56(4):343-47.

33. Torrez MNB. Construindo Uma Rede de Sustentabilidade da Implantação das Diretrizes Curriculares Nacionais do Curso de Graduação em Enfermagem., Revista Brasileira de Enfermagem, Brasília (DF) 2003 jul/ago56(4):333.

34. Henriques RLM, Rodrigues BMRD. A Formação e a Qualidade Política do Enfermeiro. Boletim Informativo da ABEn, Brasília(DF)2003 jan/ mar;45(1):5.

35.Ceribelli MIPF, Xavier IM, Fernandes JD. Diretrizes Curriculares articulação do texto e contexto - breve comentário. Boletim Informativo da ABEn, Brasília (DF) 2002; 42(2):6-7.

36. Torrez MNB. Educação e Mudanças: discutindo os contextos, textos, lições e propostas. Boletim Informativo da ABEn, Brasília(DF) 2002;42(2):2.

37.Kruse MHL, Meyer DE. Acerca de Diretrizes Curriculares e Projetos Pedagógicos: um início de reflexão. Revista Brasileira de Enfermagem, Brasília,(DF)2003 jul/ago;56(4):335-39.

38. Machado K, Henriques RBM, Pires C. Seminário Discute o Conceito de Integralidade nas Práticas de Saúde; integralidade e currículos profissionais. Rio de Janeiro, Revista Radis - Comunicação em Saúde 2003;12(14).

39. Vieira RCPA. Sobre o Ensino na Área da Saúde ou... "quem educa os educadores?" Londrina (PR), Revista Olho Mágico 2001;8(1):36-8.

40. Arendt H. A crise da Cultura. São Paulo: Forense Editora:1972.

Data de Recebimento: 20/06/2004

Data de Aprovação: 24/08/2004 